\title{
Adult Reye-like syndrome associated with serologic evidence of acute parvovirus B19 infection
}

\section{Authors}

Paulo Sérgio Gonçalves da Costa ${ }^{1}$

Geyza Machado Ribeiro ${ }^{2}$ Thiago Cardoso Vale ${ }^{3}$ Thaís Gomes Casali ${ }^{3}$

Flávio José Barbosa Leite ${ }^{4}$

${ }^{1} \mathrm{PhD}$ in Tropical Medicine, Universidade Federal de Minas Gerais (UFMG); Assistant Professor, UFMG, MG, Brazil

${ }^{2}$ Biochemist; Chief of

Laboratory, Hospital Monte Sinai, Juiz de Fora, MG,

Brazil

${ }^{3}$ Physicians; Residents, Hospital Monte Sinai, Juiz de Fora, MG, Brazil

${ }^{4}$ Physician; Clinical Director, Hospital Monte Sinai, Juiz de Fora, MG, Brazil
Submitted on: 02/08/2011 Approved on: 03/11/2011

\section{Correspondence to: Paulo Sérgio Gonçalves da Costa \\ Rua Pasteur, 164/ 1001 36015-420, Juiz de Fora, SP, Brazil \\ psgcosta@acessa.com}

We declare no conflict of interest.

(ㅇ)2011 Elsevier Editora Ltda. All rights reserved.

\begin{abstract}
Reye's syndrome is an infrequently diagnosed medical condition affecting mainly children. The etiology, epidemiology and natural history of Reye's syndrome have been cloudily written in footnotes of medical books and exotic papers since the initial description in early 1950s. We report here a case of adult Reye's syndrome associated with serologic evidence of parvovirus B19 infection.
\end{abstract}

Keywords: Reye's syndrome; parvovirus B19, human adult.

\section{CASE REPORT}

A 61 year-old white male was admitted to the ICU with loss of conscience. He reported a flu-like illness with fever and diarrhea seven days before admission. He also had type II diabetes, morbid obesity and arterial hypertension. The initial diagnostic hypothesis was transient ischemic accident (TIA) but the brain tomography showed only diffuse cerebral edema. Several blood tests were within normal range and the low Glasgow score prompted mechanical ventilation. Hemoglobin level was 16.8 g, leukocyte count 9,700, platelet count 56,000, AST 67, ALT 111, glucose 168 and prothrombim activity $41 \%$. Treatment with manitol was initiated but increased leukocyte count $(18,700)$ associated with decreased blood pressure (70 x $40 \mathrm{mmHg}$ ) required the use of empiric intravenous ampicillin, sulbactan and norephinefrine. Despite the initial low prothrombin activity, the patient had not shown any clinical (flapping, asterix or tremor) or imaging sign of liver failure. A brain MRI performed two days later did not add to the tomographic findings and a lumbar puncture revealed increased cerebrospinal fluid pressure $\left(32 \mathrm{~cm}_{\mathrm{H} 2 \mathrm{O}}\right.$ ) but was otherwise normal (3 cells, normal protein and glucose levels, negative Gram and Ziehl stainings and culture). Abdominal ultrasound remained was unremarkable but the persistent coma and increased AST, ALT and blood ammonia (all $>3$ times the upper limits of normal) along with hypertensive CSF led to Reye's syndrome diagnosis. A liver biopsy showed micro and macrovesicular steatosis with no signs of cirrhosis (Figure 1).
Figure 1: Liver biopsy showing microvesicular steatosis with no evidence of fibrosis or cirrhosis (HE. magnification 400x).

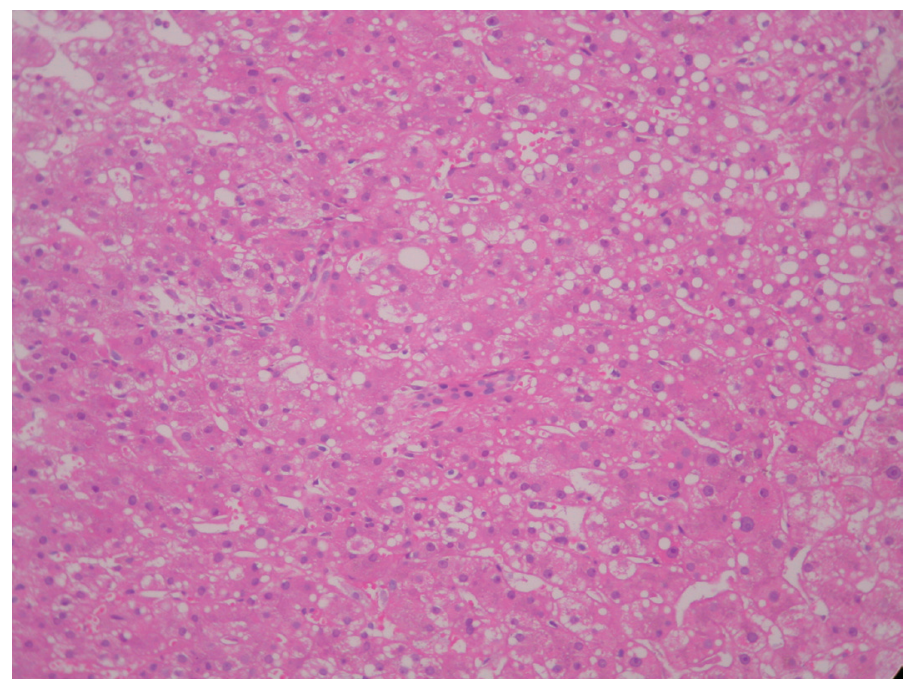


A panel of serologic, antigenic and molecular tests (hepatitis A, B, C and D, HIV, herpes simplex, dengue, influenza A, rotavirus, ANA, anti-phospholipid, mumps, leptospirosis, salmonellosis, cytomegalovirus, Epstein-Barr virus and toxoplasmosis) turned out negative or compatible with remote infection. The first (day 1) parvovivus B19 serologic test (enzymatic immunoassay) showed IgG (0.95) indeterminate and IgM (1.5) positive. The second test (day 18) showed both IgG (1.58) and IgM (2.78) positive (sensitivity and specificity $>99 \%$ ). However, PCR for parvovirus B19 was negative (day 12 sample). Despite improvement of his clinical condition, the patient developed sudden respiratory and cardiac arrest and died on day 22. No necropsy was authorized.

\section{DISCUSSION}

Reye's syndrome is an infrequently diagnosed condition affecting mainly children or patients younger than 35 years of age..$^{1-5}$ The etiology, epidemiology and natural history of Reye's syndrome remain largely unknown. The origin of the illness is unknown but failure of mitochondria function is thought to be the underline disorder. ${ }^{1,2,5}$ More recently previously unrecognized metabolic disorders were suggested as possibly associated with some cases of the illness. ${ }^{1,2,6}$ The patient here reported had Reye's syndrome according to current clinical and laboratory diagnostic criteria further confirmed by the liver biopsy findings. The absence of report of aspirin or other Reye's syndrome related drugs such as amiodarone, calcium hopantenate, valproic acid or diclofenac sodium ${ }^{1,2,6}$ does not rule out such diagnosis. Furthermore, despite the strong epidemiologic association between drugs, specially aspirin, and Reye's syndrome controversy still exists about their real role in this syndrome. ${ }^{1,2}$

Classically, Reye's syndrome has been associated with acute viral infections specially influenza $B$ or varicella zoster. ${ }^{5}$ Moreover, a wide range of viral infections like influenza A, including $\mathrm{H} 5 \mathrm{~N} 1$ strain, ${ }^{7}$ parainfluenza, rotavirus, ${ }^{8}$ hepatitis A virus, ${ }^{5}$ dengue virus, ${ }^{9}$ among others have been described as possible trigger for the disease.

Although adult Reye's and Reye-like syndrome are both uncommon and under diagnosed conditions, anecdotal reports exist. ${ }^{1-5}$ The oldest patient reported had 61 years old. ${ }^{3}$ The strong belief of Reye's syndrome as a children illness has probably been playing a role in delayed or missing diagnosis, possibly making the illness under reported.

This particular patient had serologic evidences of acute parvovirus B19 with positive IgM serology and no other identified infection. The negative PCR test in blood for parvovirus B19 did not rule out such infection since the tested sample was taken on day 12 of illness, considering the short time of viremia in parvovirus infection ranging from 4 to 10 days from the beginning of the infection. ${ }^{10}$

There is no previous reports of parvovirus B19 or any other erytrovirus infection associated to Reye's syndrome either children or adult, but we should be aware for this possibility. Reye's syndrome must be considered in non-pediatric patients since the population at risk for this condition is broader than usually believed.

\section{REFERENCES}

1. Pugliese A, Beltramo T, Torre D. Reyes and Reyes-like syndromes. Cell Biochem Funct 2008; 26:741-6.

2. Glasgow JF, Middleton B. Reye syndrome-insights on causation and prognosis. Arch Dis Child 2001; 85:351-3.

3. Peters LJ, Wiener GJ, Gilliam J et al. Reyes syndrome in adults. A case report and review of the literature. Arch Intern Med 1986; 146:2401-3.

4. Ghosh A, Pradhan S, Swami R et al. Reye syndrome: a case report with review of literature. JNMA J Nepal Med Assoc 2008; 47:34-7.

5. Duerksen DR, Jewell LD, Mason AL et al. Co-existence of hepatitis A and adult Reyes syndrome. Gut 1997; 41:121-4.

6. Forget PP, van Oosterhout M, Bakker JA et al. Partial $\mathrm{N}$-acetyl-glutamate synthetase deficiency masquerading as a valproic acid-induced Reye-like syndrome. Acta Paediatr 1999; 88:1409-11.

7. Ku AS, Chan LT. The first case of H5N1 avian influenza infection in a human with complications of adult respiratory distress syndrome and Reyes syndrome. J Paediatr Child Health 1999; 35:207-9.

8. Ioi H, Kawashima H, Nishimata $S$ et al. A case of Reye syndrome with rotavirus infection accompanied with high cytokines. J Infect 2006; 52:e124-8.

9. Iyngkaran N, Yadav M, Harun F et al. Augmented tumour necrosis factor in Reyes syndrome associated with dengue virus. Lancet 1992; 340:1466-7.

10. Heegaard ED, Brown KE. Human parvovirus B19. Clin Microbiol Rev 2002; 15:485-505. 